\title{
ELT Materials for Very Young Learners. A Teacher's Perspective on Selection, Implementation and Evaluation
}

\author{
Maria Stec \\ University of Silesia, Katowice - Cieszyn, Poland
}

\begin{abstract}
The paper will focus on ELT materials for children. The aim is to identify the most important factors linked with selection, implementation and evaluation of ELT materials currently used in kindergartens. The project involves a questionnaire study related to the materials currently used in teaching English to very young learners. The idea is to investigate the role of materials from teachers' perspective. The data will be collected in the Silesia region. It is hoped that the results from the research project will enrich the process of English education in the pre-primary stage and the process of materials development for children in pre-primary education.
\end{abstract}

\section{Introduction}

Educational policy in Europe, globalization, progress in applied linguistics and multilingualism impact of English as the international language have led to lowering the age of teaching modern languages in Europe including Poland [1]. A tendency, which has been observed for the last ten years, is to extend early language education for children who are under six-year-old [2]. It is stimulated by politicians and parents, who state that an early start to FLL (foreign language learning) will change the future of their children. Namely, children have been attending private English classes or courses frequently in Poland until 2013.

The situation is also reflected in Polish language educational system [3]. Following the latest policy of Polish Ministry of Education, a FL (foreign language) is introduced compulsorily in kindergartens since September 2015 for the fiveyear-olds, from September 2016 for the four-yearolds and September 2017 for the three-year-olds. The idea is to expose children to a FL for two main reasons. The first one is to stimulate children linguistically and culturally. The second one is to develop a positive attitude and motivation for language education. Learners are supposed to encounter a new language in a form of the plays and games, comprehend simple instructions and stories with mimes, repeat rhymes and sing songs. Teachers are supposed to combine pre-primary education with foreign language education. This introduction is a costly business on a national scale. The situation brings changes for VYL (very young learners) and teachers in kindergartens, schools as well as parents.

\section{Literature review}

An early start alone is not the solution considering characteristics of children's age factor. In Singleton's view younger means better only in the long run and under certain circumstances. There are such factors as time and frequency of the exposure to a FL that determine levels of children's proficiency. Other factors include syllabus, materials, teachers, learners' motivation and cognitive skills, international and national policy, outcomes and models, local languages and technology-mediated learning [4]. The common opinion is that children are better in learning a FL for a longer period, which will help them to achieve proficiency by the end of studies.

It is important to define VYL in this paper and they are children between 3 and 5 years old. Following Reilly and Ward's definition, they have not started to read and have not entered the schooling system [5]. They develop holistically and systematically but may differ in their developmental age as the individuals. At this age, they learn acquire the first or second language naturally namely by repeating sound patterns in new words. They understand more than they can produce as they are more receptive. Then, early language education is based on listening and later on speaking as they need the "silent" period or "the honey moon" period. They are usually fond of craft activities and TPR techniques although they may require individual attention, can be sometimes uncooperative or upset. They are affected by events at home and kindergarten or nursery school. For example, by activities interesting for them from the attractive ELT materials.

Materials are considered here as anything that supports the process of ELL and ELT at the first 
stage of early education. It involves coursebooks and textbooks, which are used here interchangeably referring to books commercially produced as core teaching materials. They can have various forms and be linguistic, visual, auditory and kinaesthetic [6]. In terms of teaching English to very young learners (TEVYL), a need is for an expanded range of ELT materials. They should be available in as many formats as possible to respond to local conditions, culture and needs. The traditional distinction is between comprehensive course series based on a syllabus (coursebooks plus workbooks, readers, CDs, posters, charts) and supplementary resources (materials for the additional work with a focus on one skills or system). ELT materials play various roles and can be informative, instructional, experiential, eliciting and exploratory [7]. They are perceived as cultural artefacts, transferring culture and values through contents and illustrations [8].

One of the most significant current discussions in language education is the interplay between local and global issues. Attention has been paid to oral skills and communication skills, adapting to local cultural norms and values. Out-of-school exposure to other languages through travelling and multimedia enables children to improve their linguistic skills [9]. The similar situation occurs in ELT materials produced for local or global audience [10], [11]. The question arises what is the extent to which they enhance English language learning experience in a particular context. Global teaching materials encompass coursebooks, workbooks, CD-ROMs, videos and online materials widely used in teaching English internationally [12]. The best solution would be glocal materials. To be precise, they are global-pluslocal coursebooks adapting the global materials to the local context of language education.

Coursebooks have been delivering language learning materials for ages and their roles have been frequently debated. A general perception of coursebooks is linked with their supportive role as they provide a language syllabus for users. They constitute a resource of the standard English for both learners and teachers even if they are not very compelling. They may reduce the time required for planning and preparation of lessons. Coursebooks are used extensively by novice teachers, who learn their teaching skills [13]. On the other hand, they are criticised for structure, irrelevant culture content, standardisation and uniformity. They do not reflect the findings of research into language acquisition. They present inaccurate and biased representation of cultural realities [14]. Global coursebooks are seen as the tools of cultural imperialism transferring only west values and culture. They are criticised for the hidden curriculum. Still, ELT materials are the engine that drives much current practice in a classroom.
An increasing concern linked with teaching practice in kindergartens is linked with attracting and maintaining preschool children's attention, adjustment of tasks to the abilities of VYL and development of the interactions during lessons. The challenges faced by teachers at this stage of schooling are associated with VYLs' cognitive development, motivation, attention, assessment and multi-level groups. A key aspect of the successful early language learning is determined by the proper conditions of learning including materials. There are a few factors which influence the way in which teachers perceive their teaching/ learning materials. Namely, the factors which affect the teachers' perception of coursebooks include:

1. experience and training (more experienced teachers tend to rely on coursebooks to a smaller degree),

2. workload (teachers working many hours at the different levels tend to depend on coursebooks more),

3. institutional policy (teachers use coursebooks more when the standard tests are based on it or supervisors insist on it),

4. quality of coursebooks (teachers use coursebooks they like more).

In practice, teachers have to select, implement and evaluate ELT materials at each stage of education. Selection of materials refers here to the process of choosing teaching materials for the use in a classroom. It is also known as the process of course book assessment divided further into two stages: evaluation for selection and analysis for implementation [15]. The evaluation for selection involves the teacher's individual decision on one course book, which can be undertaken with the help of a checklist. It is known as a predictive evaluation of ELT materials available to specify which are the best for a particular course. In practice, there are several checklists and guidelines offered for teachers in the subject literature. For the assessment of coursebooks, teachers' questions and reflections can be grouped in the four following sets:

1. questions related to the institution (e.g. curriculum, syllabus),

2. questions related to the teachers' experience and style of teaching (English level, cultural and personal factors),

3. questions related to the target learners (age, gender, needs, interest, price of ELT materials),

4. questions related to the coursebooks itself (content, layout, graphic design and pictures, teacher's book, extra materials offered) [16].

Implementation of ELT materials involves a number of responsibilities concerned with: syllabus (course book and materials) selection, materials interpretation and modification, planning courses and lessons, implementation, evaluation and identification of the changes necessary for future 
application. There are three traditional ways of using coursebooks by teachers. They can be used as the course (as the course syllabus and materials to establish what, when and how to teach English). They can be used as the syllabus and the main source of ELT materials used in the flexible manner (changing, adapting to learners' needs and teaching context). They can also be used as one small element in the course (as the material for home study while the teachers or institutions provide other materials for the course).

There is a great number of publications in Europe and the world, which support English teachers with ideas, procedures and activities for TEVYL. Namely, to start with the traditional one written by Reilly and Ward entitled Very Young Learners from 1997. To end with the one written by Pinter from 2011 entitled Children Learning Second Languages with the latest issues on child SLA and pedagogy including the distinctive chapter on resources with the list of teaching materials, journals, websites, tests, theoretical and practical books for children's practitioners and researchers.

Many publications on ELT materials mix the processes of analysis and evaluation. Evaluation can include an analysis but the objectives and procedures are different. The process of evaluation is subjective and focuses on the users of the materials, defining their effects. The process of analysis focuses on the materials to provide an objective examination of them. A general framework for analysing materials can be used before evaluation, following the sequence in the model listed below [17]:

a. analysis of the target situation of use,

b. materials analysis,

c. match and evaluation (of the materials to the target situation of use),

d. action.

Evaluation of ELT materials may refer to a retrospective evaluation. The retrospective evaluation involves the assessment of the materials after the course and implementation with the further implication for modifications. It is the complex and time consuming process that involves design of criteria, collection and analysis of the results, their interpretation and writing a report. The evaluation of materials is always based on a checklist-based system. Principles linked with theory of learning and teaching should be articulated by evaluators prior to this process [18]. To name a few in the context of this project, there is a motto saying "the earlier the better". Another assumption is that early FLL fosters motivation and positive attitude to a FL. The closing principle refers to the time and intensity of the course, which influence children's language achievements.

Most studies in ELT materials have focused on the selected coursebooks, which are being supported or criticised, for example attitudes to cultural content or visual content in ELT materials [19]. However, far too little attention has been paid to materials selection, implementation and evaluation for the preprimary stage of language education. Teachers may improve their skills in selecting, implementing and evaluating ELT materials as well as in materials research. This research study and project may stimulate some reflections in FL teachers themselves, who are going to teach modern languages to children. They have already been participating in "materials development" through the use of materials for ELL including their design, production, adaptation and assessment [20].

\section{Research project}

To investigate the issue of ELT materials in Polish kindergartens, the following research project has been designed including the research objectives, questions, procedures and tools.

\subsection{Research objectives and questions}

The major objective of this project is to investigate the role of ELT materials in the process of teaching English to VYL. The idea is to examine challenges in the process of selection, implementation and evaluation of materials faced by English teachers in kindergartens. The research questions designed for this project are divided into three groups. The first one focuses on the selection of ELT materials for VYL. The second group of questions refers to the process of their implementation and the third one to the process of their evaluation. The following research questions are grouped:

1. What is the process of selecting ELT materials for VYL?

a. How do teachers select ELT materials for VYL?

b. What are the challenges faced by teachers in the selection of ELT materials?

2. What is the process of implementing ELT materials for VYL?

a. What type of ELT materials are used in Polish kindergartens?

b. How are ELT materials implemented in TEVYL?

c. What are the challenges faced by teachers in the implementation of ELT materials in kindergartens?

3. What is the process of evaluating ELT materials for VYL?

a. How do teachers evaluate ELT materials?

b. What are the challenges faced by teachers in the evaluation of ELT materials in kindergartens? 


\subsection{Research procedures and tools}

The research project was conducted in a form of the questionnaire study. Thirty questionnaires were distributed among English teachers in kindergartens in the Silesia region in the spring 2015. The respondents had one week to complete them. Finally, twenty-two questionnaires were collected. The research tool was a questionnaire designed for English teachers in Polish kindergartens. The questionnaire was written in Polish and divided into two parts. The first part was concerned with the background information of the respondents (gender, experience, qualifications for teaching English to children) and includes nine questions. This part was formed only to depict the selected number of teachers participating in the investigation. The second part of the questionnaire was more detailed and focused on ELT materials for VYL. This part includes sixteen questions, both open and closed ones. In particular, the respondents were to answer the questions about the process of selecting, implementing and evaluating ELT materials for children in Polish kindergartens.

\section{Presentation of the results}

The results gathered in the first part of the research study depicted that twenty-two respondents participated in the project. A majority of them were between 25 and 30 years old $(46 \%)$. The others constituted the groups of 20-24 years old, 31-39 years old and 40-50 years old with the respective 18 $\%$ per each group. All of them were English teachers working in both kindergartens and primary schools.

11 respondents have been teaching English in kindergartens for up to two years; 5 of them have had the same experience for 5 years and also 5 of them have had the longest experience teaching for up to fifteen years. Still, all them have been working in the primary schools and are assumed to know the first stage of language education. As far as their English level is concerned, $73 \%$ of them claimed to be at $\mathrm{C} 1$ level, $23 \%$ at B2 level and only $4 \%$ at B1 level following the Common European Framework of Reference. The respondents' qualifications for teaching English to VYL vary to a certain extent. The results showed that $50 \%$ of the respondents had a BA degree in English, 23\% also a BA degree but in pedagogy, 18\% achieved a MA degree in English and $9 \%$ of them completed courses such as FCE or CAE in English plus methodology courses. The teachers participating in the project showed a different workload. $48 \%$ of them taught between 1 and 3 English lessons per week, 26\% taught between 4 and 6 lessons while $4 \%$ of them between 7 and 10 lessons and also 4\% between 11 and 15 lessons, $18 \%$ taught between 16 and 30 lessons. A vast majority of the respondents work in the villages $(68 \%)$ and the rest $(32 \%)$ in the towns of the Silesia region.

The results from the second part of the questionnaire depict the teachers' attitude to ELT materials and conditions of teaching. $41 \%$ of them claimed that they were not supported by headmasters with ELT materials, 23\% experienced small support while only $13 \%$ encountered a lot of support. There was a group of $23 \%$ who did not answer this question. Considering teaching conditions, the general tendency was to teach English in a standard kindergarten classroom (67\%) with carpets, toys, small tables and a TV set. Another part of the results (33\%) related to a well-equipped classroom with a big screen and an interactive whiteboard.

Asking about criteria used during the selection of ELT materials for this early stage of education, they provided the following answers. The teachers' attention focused on practicality (32\%), content $(30 \%)$, structure, design and pictures $(21 \%)$. To a lesser degree they were careful about price (14\%) and publishers $(3 \%)$. The process of selecting ELT materials varied to a considerable degree. $23 \%$ of the respondents tended to analyse VYLs' abilities to choose teaching materials for them. $18 \%$ of them searched on the Internet to find the best materials possible, $14 \%$ asked the professional publishers and read teaching magazines, $14 \%$ designed the materials themselves and $13 \%$ of them followed their experience and intuition. Similarly, 9\% of them analysed contents in the materials while also $9 \%$ provided any answer to the question. As far as syllabuses were concerned, $68 \%$ of the respondents designed a syllabus themselves. A less popular was the use of syllabuses suggested by publishing houses (32\%). Searching for English materials, the teachers used their own resources $(36 \%)$ or consulted publishers' representatives (26\%). Another solution was to search in bookshops (19\%) or on the Internet $(16 \%)$. They followed also other possibilities such as sharing the opinions with colleagues (3\%). Considering the elements important for the selection of ELT materials, the results were grouped in four major categories. The first category was supported by $41 \%$ of the respondents and included time, experience and money. The second category, which was supported by $32 \%$ of them, included reflections on VYLs' needs and skills. The teachers' creativity constituted the third category of requirements maintained by $18 \%$ of the respondents and the fourth one was supported by $9 \%$ referring to knowledge about syllabus.

Investigating the process of implementation, the requirements were grouped into five types. The first category, having been supported by $27 \%$ of the teachers, related to the adjustment of ELT materials to VYLs' level. The second category related to time consuming preparation stated by $23 \%$ of the participants. The third category focused on 
knowledge of VYLs' skills and was supported also by another $23 \%$ of the teachers. The fourth category underlined teachers' patience and learners' repetitions and was declared by $14 \%$ of the respondents. Finally, the fifth category focused on teachers' creativity and commitment, which was supported by $13 \%$ of the respondents.

Asking the respondents about the frequent use of the selected materials brought a wide variety of responses. The major tendency is to use coursebooks always (18\%), very often (14\%) and often $(23 \%)$. Another tendency is to use them infrequently (27\%) or use them sometimes (18\%) in kindergartens.

In the context of kindergarten, the use of toys and puppets during English lessons is very popular. 36\% of the respondents use them always, $23 \%$ very often and $27 \%$ often. Only $5 \%$ use them sometimes and $9 \%$ use them rarely. The similar results are gathered for the use of pictures and DIY (do-it-yourself materials) as the majority of the teachers (64\%) had a tendency to use always these materials, $9 \%$ use them very often and $4 \%$ use often. Only $5 \%$ use them sometimes and $18 \%$ rarely. The more detailed investigation of pictures used in for kindergartens brought the following results. The pictures of objects (food, clothes, toys) were used by $23 \%$ of the respondents during English lessons in kindergartens. Similarly, the pictures of people in action (jobs) were implemented by $20 \%$ of the participants. The pictures of famous characters (characters) were as popular as the pictures of symbols having been used by $18 \%$ of them in both cases. As far as the evaluation of structure, design and pictures in ELT materials are considered, the participants underlined five factors. $29 \%$ of the teachers focused on the supportive role of the structure and graphics in ELT materials. $18 \%$ of the respondents paid attention to their stimulating role in discussions. 7\% underlined their role in the transfer of culture. $20 \%$ stressed their impact on children's cognitive development and $26 \%$ their impact on visual perception of VYL.

Asking about the frequency of using realia, instruments and games, there is a gap between the frequent use of these materials (27\% use always, $18 \%$ use very often and $9 \%$ use often) and the infrequent use admitted by the teachers (37\% use rarely and $9 \%$ use sometimes). Investigating the types of materials prepared by the teachers themselves, they defined four following groups. $32 \%$ of the respondents had a tendency to prepare their own games, work records and flashcards. Likewise, $32 \%$ stated the same about pictures and illustrations used in English lessons in kindergartens. In the same way, $18 \%$ of them had a tendency to prepare realia and toys for VYL and also $18 \%$ of them claimed to prepare all the materials. The frequency of using multimedia during English lessons in kindergartens vary from the infrequent use (9\% rarely and $36 \%$ use them sometimes) to more regular ones $(14 \%$ use them always, $18 \%$ use often and $23 \%$ of them use multimedia very often).

Describing difficulties with the implementation of ELT materials, the teachers grouped five sets of problems. The biggest group of problems (stated by $32 \%$ of the teachers) was linked with keeping discipline and children's short attention span. $23 \%$ of the participant listed difficulties with the selection of ELT materials. Also 23\% of the respondents faced difficulties with their adjustment to children's' age and abilities. Another source of difficulties related to a big number of learners in groups (up to 20) (13\%) and to the use, size and number of available ELT materials $(9 \%)$.

As far as the evaluation of ELT materials for kindergartens is concerned, $33 \%$ of the respondents claimed that evaluation of ELT materials requires experience and preparation. $24 \%$ stated that it involves knowledge of VYLs' level and $10 \%$ that it requires investment in teachers' work. $9 \%$ stated that this process involves a reflection on the materials used earlier. However, $24 \%$ of them did not provided any comments on the matter. As far as the evaluation of structure, design and pictures in ELT materials, the participants underlined five factors. $29 \%$ of the teachers focused on the supportive role of the structure and graphics in ELT materials. $18 \%$ of the respondents paid attention to their stimulating role in discussions. $7 \%$ underlined their role in the transfer of culture. $20 \%$ stressed their impact on children's cognitive development and $26 \%$ their impact on visual perception of VYL.

\section{Discussion of the findings}

The present results are significant in at least major three respect. The first one describes the process of selecting ELT materials for VYL in Polish kindergartens. Initially, teachers tend to check their resources, follow DIY and search in bookshops, Internet or consult publishers' representatives. The most common criteria used by them in terms of the materials include practicality, content, structure and design of the materials. They are aware that this process requires time, experience and money but is possible only after a careful reflection on VYLs' needs and skills. The popular ELT materials used in Polish kindergartens include toys, puppets, DIY materials, coursebooks and multimedia.

The second respect defines the process of implementing ELT materials in kindergartens, which vary to a considerable degree. The most popular materials used during English lessons embrace toys and puppets, pictures and DIY materials. In particular, the pictures of objects, people in action, famous characters and symbols are generally used by English teachers. There is an extensive amount of ELT materials prepared by the teachers themselves 
such as games, work records, flashcards and illustrations for particular English lessons. The challenges faced in the implementation of the materials are linked mainly with discipline problems in a group and children's short attention span. Another set of challenges involves difficulties with the selection of the proper materials for VYL and adjustment to their skills and abilities. The study has shown that the process of implementation requires teachers' good skills in the adjustment of ELT materials to the level of VYL. It also requires teachers' time consuming preparation and good knowledge of children's skills.

The third respect describes the process of evaluating ELT materials for children in kindergartens. It is challenging as it requires experience and preparation, knowledge of children's level and reflection on the materials already used. In particular, teachers tend to assess structure, design and pictures in ELT materials in terms of their supportive role for teaching VYL (development of children's' visual perception and cognitive development).

The findings have important implications for materials development in the context of early language education. Majority of these issues, which emerged from the findings, relate specifically to teachers - practitioners' perception and using of ELT materials in this early stage of education.

\section{Conclusions}

The investigation was undertaken to describe teachers' challenges with ELT materials in the context of newly introduced policy of teaching foreign languages at the stage of pre-primary education in Poland. Although the current research study is based on a small sample of participants, who work as English teachers with various qualifications and experience in TEVYL, the findings suggest that they need support and training with ELT materials. The study has shown that there is a need for training in the field of selection, implementation and evaluation as there are many opportunities and ready-made materials available on the market. The findings enhance our understanding of materials development and early foreign language education in kindergartens. Further research is required on the most effective types of ELT materials used with VYL including teacher's books. Another investigation may refer to their appropriateness for this age group.

\section{References}

[1] J. Enever, and J. Moon, "New global contexts for teaching Primary ELT: change and challenge". In: J. Enever, J. Moon, and U. Raman (eds.) Young Learner
English Language Policy and Implementation: international perspectives, Reading, Garnet Publishing, 2009 , pp. 5-20.

[2] S. Rixon, "British Council Survey of Policy and Practice in Primary English Language Teaching Worldwide", London, British Council, Brand and Design, 2013.

[3] S. Garton, F. Copland, and A. Burns, "Investigating Global Practices in Teaching English to Young Learners", ELT Research papers 11-01. British Council, London, Birmingham, Aston University, 2011, pp. 1-24.

[4] R. Johnstone, "An Early Start: What are the Key Conditions for Generalized Success? In: J. Enever, J. Moon, and U. Raman (eds.) Young Learner English Language Policy and Implementation: International Perspectives), Reading, Garnet Publishing, 2009, pp. 3141.

[5] V. Reilly, and S. Ward, "Very Young Learners", Oxford, OUP, 1997.

[6] B. Tomlinson, "Materials Development". In: R. Carter and D. Nunan (eds.), The Cambridge Guide to Teaching English to Speakers of Other Languages, Cambridge, CUP, 2001, pp. 66-71.

[7] B. Tomlinson, "State-of-the-Art Article. Materials Development for Language Learning and Teaching. Language Teaching, vol. 45.2, doi:10.1017/ S0261444811000528, pp. 143-179, 2012.

[8] A. P. Litteljohn, "Language Teaching Materials and the (Very) Big Picture", Electronic Journal of Foreign Language Teaching, vol. 9/1, 2012, pp. 283-297.

[9] J. Enever, and J. Moon, "New Global Contexts for Teaching Primary ELT: Change and Challenge". In: J. Enever, J. Moon, and U. Raman (eds.) Young Learner English Language Policy and Implementation: International Perspectives, Reading, Garnet Publishing, 2009 , pp. 5-20.

[10] I. Freebairn, "The Coursebooks - Future Continuous or Past? English Teaching Professional, vol.15, April, 2000, pp. 3-5.

[11] I. McGrath, "Teaching Materials and the Roles of EFL/ESL Teachers", London, Bloomsbury, 2013.

[12] G. Hadley, "Global Textbooks in Local Contexts. An Empirical Investigation of Effectiveness". In: N. Harwood (ed.) English Language Teaching Textbooks. Content, Consumption, and Production, London, Palgrave Macmillan, 2014, pp. 205-238.

[13] I. McGrath, "Teaching Materials and the Roles of EFL/ESL Teachers", London, Bloomsbury, 2013.

[14] P. Byrd, "Textbooks: Evaluation for Selection and Analysis for Implementation". In: M. Celce-Murcia (ed.) Teaching English as a Second or Foreign Language, Boston, Heinle and Heinle, the Thomson Learning. 2001, pp. 415-428. 
[15] P. Davies, and E. Pearse, "Success in English Teaching", Oxford, OUP, 2000.

[16] A. P. Litteljohn, "The Analysis of Language Teaching Materials: Inside the Trojan Horse. In: B. Tomlinson (ed.) Materials Development for Language Teaching, Cambridge, CUP, 2011, pp. 179-211.

[17] B. Tomlinson, "Materials Evaluation". In: B. Tomlinson (ed.). Developing Materials for Language Teaching, London, Bloomsbury Academic, 2013, pp. 2148.

[18] J. Gray, "The ELT Coursebooks as Cultural Artefacts: How Teachers Censor and Adapt, ELT Journal, vol. 54/3, 2000, pp. 274-283.

[19] M. Stec, "Evaluation of ELT Materials for Young Learners: Course Books as Cultural Artefacts". In: A. Akbarov (ed.). The Practice of Foreign Language Teaching. Theories and Applications, Cambridge, Cambridge Scholars Publishing, 2015, pp. 517-527.

[20] J. Crawford, "The Role of Materials in the Language Classroom: Finding the Balance". In: J. C. Richards and W. A. Renandya (eds.), Methodology in Language Teaching, Cambridge, CUP, 2002, pp. 80-92. 